\title{
Air pollutants Emission inventory from offshore fishery research vessel
}

\author{
Xin $\mathrm{Rao}^{1,2}$, Hongliang Huang ${ }^{1,2^{*}}$, Lingzhi $\mathrm{Li}^{1,2}$, Shuai Chen ${ }^{1,2}$, and Jialiang Yang ${ }^{1,2}$ \\ ${ }^{1}$ Key Laboratory of Oceanic and Polar Fisheries, Ministry of Agriculture; East China Sea Fisheries Research Institute, Chinese Academy \\ of Fishery Sciences, Shanghai, 200090, China \\ ${ }^{2}$ Engineering Technology Research Center of Marine Fishing, Chinese Academy of Fishery Sciences, Shanghai, 200090, China
}

\begin{abstract}
With the development of offshore and Pelagic Fisheries, the continuous expansion of fishing routes, the corresponding ship tonnages are increasing, and the air pollution of vessels is becoming more and more serious. An offshore fishery research vessel was selected as the object, the emission factors were obtained according to its basic data, the method based on fuel consumption was adopted to calculate the air pollutants emission ( $\mathrm{NO}_{x}, \mathrm{HC}, \mathrm{CO}$ and $\left.\mathrm{PM}_{10}\right)$ and the emission inventory was established. The inventory provides data for the establishment of the emission inventory of offshore pelagic fishery in the future, and has positive significance for the establishment of green fishing in the future.
\end{abstract}

\section{Introduction}

With the vigorous development of fishing equipment and technology, the promotion of economic benefits, offshore and pelagic fisheries have rapidly developed in China. With the continuous expansion of fishing routes, the corresponding ship tonnages are increasing, and the air pollution of vessels is becoming more and more serious, even to the point that can not be ignored. Especially in some sea areas and ports with dense routes and large vessels, the air pollutants emission of vessels even become the main source of pollution in these areas ${ }^{[1]}$.

There are several kinds of pollutants from vessels: particulate matter, nitrogen oxides, carbon oxides, hydrocarbon and other harmful gases, which seriously threaten human health ${ }^{[2]}$. Particulate matter is generally formed by the condensation of hundreds volatile and semi volatile substances on the carbon core ${ }^{[3]}$, which can lead to body inflammation, asthma and cardiopulmonary disease $^{[4,5]}$. During the formation and growth of the particles, the oxidation of carbon and initial particles occurs simultaneously to form gaseous products such as $\mathrm{CO}$ and $\mathrm{CO}_{2}$. Under certain conditions, $\mathrm{NO}_{\mathrm{x}}$ will generate secondary pollution-photochemical smog, causing greater harm to human body. $\mathrm{NO}_{\mathrm{x}}$ has become one of the main pollution sources of urban today ${ }^{[6]}$. Marine vessels are the main source of nitrogen oxides $\left(\mathrm{NO}_{\mathrm{x}}\right)$ emissions in the world $^{[7]}$. In 2007, ocean ships emitted about 5 million tons of $\mathrm{NO}_{\mathrm{x}}$, accounting for $15-30 \%$ of global $\mathrm{NO}_{\mathrm{x}}$ emissions ${ }^{[8]}$.

$\mathrm{T}$ S Jin et al. investigated the overall situation of transport ships in Tianjin port, and reasonably selected emission factors according to their emission control level ${ }^{[9]}$; then based on the method of fuel consumption, the $\mathrm{NO}_{\mathrm{x}}, \mathrm{HC}, \mathrm{CO}$ and $\mathrm{PM}_{10}$ emissions from transport ships in
Tianjin port in 2006 were calculated, and the emission inventory of air pollutants from transport ships in Tianjin Port was established. Finally, the emission inventory of air pollutants from transport ships in Tianjin port in 2010 and 2020 was predicted.

Based on the collected data of non road mobile source activities in the Pearl River Delta, L J Zhang et al. established the 2006 non road mobile source emission inventory in the Pearl River Delta region by using the estimation methods and emission factors suitable for all kinds of non road mobile source emissions. It is concluded that cargo ships are the main emission sources, and their emissions of $\mathrm{SO}_{2}, \mathrm{NO}_{\mathrm{x}}, \mathrm{VOC}, \mathrm{CO}$ and $\mathrm{PM}_{10}$ account for $89.8 \%, 81.8 \%, 77.3 \%, 79.5 \%$ and $81.7 \%$ of the total emissions respectively ${ }^{[10]}$.

In this paper, an offshore fishery research vessel is selected as the research object. The vessel carried out the coastal fishery resources investigation project in the East China Sea in 2020. The mission time is 91 days, and has completed the data collection work of more than 300 stations. In this paper, the emission factors of the research vessel are selected according to the investigation situation. Based on the method of fuel consumption, the air pollutant emissions $\left(\mathrm{NO}_{\mathrm{x}}, \mathrm{HC}, \mathrm{CO}\right.$ and $\left.\mathrm{PM}_{10}\right)$ of the research vessel in 2020 are calculated, and the emission inventory is established. The inventory provides data for the establishment of the emission inventory of offshore and pelagic fishery in the future, and has positive significance for the establishment of green fishing.

\section{Method}

For the estimation of air pollution emissions from ships, there are two methods: Based on power and based on fuel consumption. The research vessel has clear working 
conditions, fuel consumption estimation is relatively accurate, and the main engine on board has fuel consumption recorder, which can record fuel consumption data in real time. Therefore, this paper selects the method based on fuel consumption estimation [9]. In this paper, firstly according to the survey data and the domestic emission inventory data, the reasonable emission factors are selected. Secondly, the fuel consumption of the vessel is estimated according to the working conditions, and then the air pollutant emissions of the vessel in 2020 are obtained by multiplying.

$$
I_{\mathrm{i}}=E_{i} * C_{f}
$$

Where, $I_{i}$ is the emission of a certain pollutant(t/a), $E_{i}$ is the emission factor $(\mathrm{g} / \mathrm{L})$ of a certain pollutant, and $C_{f}$ is the fuel consumption $\left(10^{6} \mathrm{~L} / \mathrm{a}\right)$.

\section{Results}

\subsection{Emission factors}

The research on emission factors in China is in the initial stage. At present, there is no mature emission inventory calculation model. Domestic researchers generally use the immature off road model to estimate the total emission through fuel consumption. Therefore, the domestic ship emission factors are obtained by the method of investigation and estimation. It should be noted that in the process of calculating ship emission inventory based on fuel consumption, various data are needed, such as ship carrying capacity, ship sailing distance, fuel consumption rate, emission factor, etc. These data are obtained by statistical data, and there are many uncertain factors, so that the research results will have great differences.

In 2002, G L Nian et al. ${ }^{[11,12]}$ investigated the main engine types of large ships in the shipbuilding industry, and estimated the ship emission factors in China, as shown in Tables 1and 2. Based on these two tables, referring to the power parameters of the main engine and auxiliary engine of the research vessel, according to the type of fuel (marine fuel of main engine, diesel of auxiliary engine), power $(630 \mathrm{kw}$ of main engine and $75 \mathrm{~kW}$ of auxiliary engine during navigation, $475 \mathrm{kw}$ of main engine and $190 \mathrm{kw}$ of auxiliary engine during operation) and time ( emission factor is based on 2002, this research vessel project is on 2020 , with $15 \%$ emission control), as shown in Table 3.

Table1. Emission factors in ship emission estimation of China in 2002

\begin{tabular}{|c|c|c|c|c|c|}
\hline Fuel & Power & $\mathrm{NO}_{\mathrm{x}} / g \cdot L^{-1}$ & $\mathrm{HC} / g \cdot L^{-1}$ & $\mathrm{CO} / g \cdot L^{-1}$ & $\mathrm{PM} 10 / g \cdot L^{-1}$ \\
\hline \multirow{2}{*}{ Marine fule } & ALL & 65.450 & 2.856 & 7.260 & 3.930 \\
\hline & $<746$ & 41.013 & 4.058 & 7.628 & 2.023 \\
\hline \multirow{2}{*}{ Diesel } & $746-1492$ & 54.924 & 2.856 & 6.283 & 2.023 \\
\hline & $>1492$ & 46.612 & 1.999 & 9.318 & 2.023 \\
\hline & Table2. & \multicolumn{4}{|c|}{ Emission factors of inland river ships in 2002} \\
\hline Power & $\mathrm{NO}_{\mathrm{x}}$ & $\mathrm{HC}$ & $\mathrm{CO}$ & $\mathrm{PM}_{10}$ & unit \\
\hline$<373 K W$ & 389.3 & 51.1 & 47.3 & 17 & $l b \cdot \mathrm{Kgal}^{-1}$ \\
\hline 373-746KW & 300 & 17.1 & 80.9 & 17 & $l b \cdot \mathrm{Kgal}^{-1}$ \\
\hline $\begin{array}{c}\text { Average } \\
\text { emission } \\
\text { factors }\end{array}$ & 41.358 & 4.092 & 7.692 & 2.04 & $g \cdot L^{-1}$ \\
\hline
\end{tabular}

Table3. Emission factors of research vessel

\begin{tabular}{cccccc}
\hline & $\mathrm{NO}_{\mathrm{x}}$ & $\mathrm{HC}$ & $\mathrm{CO}$ & $\mathrm{PM}_{10}$ & unit \\
\hline Main engine & 34.86 & 3.45 & 6.48 & 1.72 & $g \cdot L^{-1}$ \\
$\begin{array}{c}\text { Auxiliary } \\
\text { engine }\end{array}$ & 39.72 & 5.21 & 4.83 & 1.72 & $g \cdot L^{-1}$ \\
\hline
\end{tabular}

\subsection{Fuel consumption estimation}

According to the original factory design, the oil consumption of main and auxiliary engines is $200 \mathrm{ml} /(\mathrm{h} * \mathrm{kw})$, the full load power of the main engine is $510 \mathrm{kw}$, the auxiliary engine is $200 \mathrm{kw}$, the rated power of the main engine is $634 \mathrm{kw}$, the auxiliary engine is $250 \mathrm{kw}$, the output power during navigation of the main engine is $630 \mathrm{kw}$, the auxiliary engine is $75 \mathrm{kw}$, the output power during operation of the main engine is $475 \mathrm{kw}$ and the auxiliary engine is $190 \mathrm{kw}$. The total voyage time is 91 days, including 300 hours of operation time and 1884 hours of navigation. The estimated fuel consumption 
formula is as follows:

$$
C_{f}=T * 200 *(O P / L P) * R P
$$

Where, T is time, OP is output power, LP is full load power and RP is rated power. According to the above estimation formula, the fuel consumption is the sum of navigation consumption and operation consumption. The fuel consumption of main engine is 330530.31, and that of auxiliary engine is 495751 .

\subsection{Emission inventory calculation}

According to above parameters, the air pollutant emissions of the research vessel in 2020 are calculated as shown in Table 4. The results show that the total emission of air pollutants from the vessel in 2020 is 17.905 tons. In addition to the sulfur oxide emissions not involved in this study, the total emissions are estimated to be in the volume level of 20-30 tons. Among all the air pollutants, $\mathrm{NO}_{\mathrm{x}}$ emissions account for $75 \%$ of the total emissions of this study, which is the most important emission in the future control.

Table4. Emission amount of atmospheric pollutants

\begin{tabular}{cccccc}
\hline & $\mathrm{NO}_{\mathrm{x}}$ & $\mathrm{HC}$ & $\mathrm{CO}$ & $\mathrm{PM}_{10}$ & unit \\
\hline $\begin{array}{c}\text { Main } \\
\text { engine }\end{array}$ & 11.5 & 1.14 & 2.14 & 0.57 & $t$ \\
$\begin{array}{c}\text { Auxiliary } \\
\text { engine }\end{array}$ & 1.97 & 0.26 & 0.24 & 0.085 & $t$ \\
Sum & 13.47 & 1.40 & 2.38 & 0.655 & $t$ \\
\hline
\end{tabular}

\section{Disscusion}

The main engine of the research vessel has a fuel consumption recorder, which can record the fuel consumption data in real time and is relatively accurate. The auxiliary engine has no fuel consumption record, so it can only be measured or estimated theoretically. In the future, according to the real-time fuel consumption data and GPS data, the spatial distribution of emission inventory can be drawn to provide data and ideas for future emission control.

The research on emission factors is the most important in the calculation of emission pollutants at present stage in China. In the future, it can be considered to install exhaust flow meter, exhaust gas analyzer and particulate matter tester on board, and obtain the measured emission factors and real-time fuel consumption. Compared with the emission factor selected in this study, its accuracy and applicability are analyzed.

The calculation of fuel consumption in this study is an ideal fuel consumption. In practice, the current direction, towing speed and wind direction will affect the fuel consumption, and these uncertain factors are very difficult to quantify, and also difficult to ensure the accuracy through the estimation. In the future, we can compare the real-time fuel consumption data with the estimated fuel consumption, improve the fuel consumption calculation method and establish the fuel consumption estimation model.

\section{Acknowledgments}

The authors would like to thank the support of Clean coasts by harvesting and reusing bloomed jellyfish at right time point(2017YFE0111100)

\section{References}

1. Fu,Q.Y.,Chen,M.H.,Qian,H.(2001) The status quo and share responsibility rate of $\mathrm{NOx}$ pollution in Shanghai.Shanghai environmental science, 20(5):224-226

2. Dong,H.Y.,Shuai,S.J.,et al.(2007) The latest development and development trend of diesel engine exhaust aftertreatment technology. Small Internal Combustion Engine and Vehicle Technique, (6):87-91

3. Zhao,R.R..(2011) Study on emission characteristics of diesel engine equipped with particulate filter.Beijing technology university Press,Beijing,1150 .

4. Y,H.H., Xu,Y., Xiao,Z.C. (2001) Research on diesel vehicle exhaust after treatment. Environmental science research, 14(4): 54-56.

5. Wang,T.Y.,Lin,K.S.,Lin,M.Q.,et al.(2007) Study on characteristics of particle capture and forced regeneration of fuel catalytic particulate filter.Journal of internal combustion engine, 25(6): 527-531.

6. Lu,X.M.(2006) Study on combustion process and PAHs emission characteristics of Bio diesel Engine.Beijing technology university Press,Beijing,1-100 .

7. Wang,H.,Liu,D.,Dai,G.(2009) Review of Maritime Transportation Air Emission Pollution and Policy Analysis. Journal of Ocean University of China, 8(3).

8. Corbett,J.J.,Kohler,H.W.(2003) Updated emissions from ocean shipping. Journal of Geophysical Research,108(D20):4650.

9. Jin,S.T.,Yin X.G.,Xu,J.,et al.(2009) Air pollutants emission inventory from commercial ships of Tianjin Harbor.Marine environmental science,28(6): 623-625. 
10. Zhang,L.J.,Zhen,J.Y.,Ying,S.S.(2010) Development of Non . road M obile Source Emission Inventory for the Pearl River.Environmental science,(4): 886-891.

11. Ynag,L.(2005)Emission inventory of air pollutants from transport vessels in China and typical port cities.Department of environmental science and engineering, Tsinghua University press, Beijing, 0100 .

12. Nian,G.L(2004) Study on national emission inventory of non road mobile source pollutants. Department of environmental science and engineering, Tsinghua University press, Beijing, 0100 . 